Article

\title{
Graphene/Ruthenium Active Species Aerogel as Electrode for Supercapacitor Applications
}

\author{
Arnaud Gigot 1,2,*, Marco Fontana ${ }^{2}$, Candido Fabrizio Pirri ${ }^{1,2}$ and Paola Rivolo ${ }^{2}$ \\ 1 Center for Sustainable Future Technologies, Istituto Italiano di Tecnologia, 10129 Torino, Italy; \\ fabrizio.pirri@polito.it \\ 2 Dipartimento di Scienza Applicata e Tecnologia, Politecnico di Torino, 10129 Torino, Italy; \\ marco.fontana@polito.it (M.F.); paola.rivolo@polito.it (P.R.) \\ * Correspondence: Arnaud.gigot@polito.it; Tel.: +39-011-090-7343
}

Received: 20 November 2017; Accepted: 26 December 2017; Published: 30 December 2017

\begin{abstract}
Ruthenium active species containing Ruthenium Sulphide $\left(\mathrm{RuS}_{2}\right)$ is synthesized together with a self-assembled reduced graphene oxide (RGO) aerogel by a one-pot hydrothermal synthesis. Ruthenium Chloride and L-Cysteine are used as reactants. The hydrothermal synthesis of the innovative hybrid material occurs at $180{ }^{\circ} \mathrm{C}$ for $12 \mathrm{~h}$, by using water as solvent. The structure and morphology of the hybrid material are fully characterized by Raman, XRD, XPS, FESEM and TEM. The XRD and diffraction pattern obtained by TEM display an amorphous nanostructure of $\mathrm{RuS}_{2}$ on RGO crystallized flakes. The specific capacitance measured in planar configuration in $1 \mathrm{M}$ $\mathrm{NaCl}$ electrolyte at $5 \mathrm{mV} \mathrm{s}^{-1}$ is $238 \mathrm{~F} \mathrm{~g}^{-1}$. This supercapacitor electrode also exhibits perfect cyclic stability without loss of the specific capacitance after 15,000 cycles. In summary, the RGO/Ruthenium active species hybrid material demonstrates remarkable properties for use as active material for supercapacitor applications.
\end{abstract}

Keywords: reduced graphene oxide; aerogels; ruthenium sulphide; supercapacitor; hybrid nanocomposite

\section{Introduction}

Recently, the need for energy storage systems has become crucial for smart energy management. Supercapacitors are electrochemical power storage devices that can have many practical applications, replacing or working alongside existing battery technology. The main advantages of supercapacitors compared to batteries are their higher power density values, their much longer cycle life, and their fast charge/discharge rate. The fabrication of nanostructured electrodes improves their energy density without affecting their high power density $[1,2]$.

As is well-known, supercapacitors can be divided into two main classes based on different energy storage mechanisms: Electrochemical Double-Layer Capacitors (EDLCs) and Pseudo-Capacitors (PCs). In EDLCs, the storage is based on the adsorption of both anions and cations at the interface between a high surface area electrode and an electrolyte. Typically, porous carbon materials are investigated as electrodes due to their high specific surface area, electrical conductivity and pore size and distribution, which are the main properties. In particular, a self-assembled graphene-based three-dimensional nanoarchitecture aerogel has already been studied by the scientific community and attracted our attention because of its outstanding performance [3-8]. As far as concerns PCs, which store energy through fast surface redox reactions (Faradaic processes), they were examined to obtain higher specific capacitance. Usually, metal oxides such as $\mathrm{RuO}_{2}$ [9-13], $\mathrm{MnO}_{2}$ [14-16], $\mathrm{Co}_{2} \mathrm{O}_{3}$ [17], $\mathrm{NiO}$ [18], $\mathrm{SnO}_{2}$ [19], $\mathrm{V}_{2} \mathrm{O}_{5}$ [20-22], $\mathrm{NiCo}_{2} \mathrm{O}_{4}$ [23] are used as pseudocapacitors. Numerous experiments have established that $\mathrm{RuO}_{2}$ is the material for pseudocapacitors, which offers the best performance due to its highly reversible charge-discharge features, excellent electrical conductivity and ultrahigh pseudocapacitance [24]. 
In order to increase the energy density of electrodes for supercapacitors, hybrid materials that combine the properties of both EDLCs and PCs have been developed [25]. Basically, a pseudocapacitive material is synthesized together with a graphene-based aerogel [26-31]. These hybrid supercapacitors have the advantage of offering an enhancement of the cycling life of the pseudocapacitive material, an increase of the specific capacitance and avoiding the restacking of the graphene flakes due to the presence of the pseudocapacitive material. In particular, a graphene-based aerogel containing $\mathrm{RuO}_{2}$ nanoparticles has already been extensively investigated during the past two decades and has demonstrated good performance [24].

More recently, transition metal dichalcogenide (TMD) mono- and multi-layered sheets have generated considerable research interest due to their unusual physical, chemical and electronic properties compared to their bulky counterparts, along with the great affinity with graphene due to their 2D-layered structure [32,33]. Numerous TMDs have been studied in depth in the literature, for instance $\mathrm{MoS}_{2}$ [34-38], $\mathrm{TiS}_{2}[39,40], \mathrm{WS}_{2}[36,41], \mathrm{MoSe}_{2}[37,38]$ and $\mathrm{WSe}_{2}[37,42]$. In addition, some of these have been reported as outstanding materials in a hybrid configuration for supercapacitor applications, such as $\mathrm{MoS}_{2}[43-46]$ and $\mathrm{WS}_{2}[47,48]$.

Although hybrid supercapacitors containing TMDs have demonstrated better performance, only a limited number of hybrids is reported in the literature [49]. Furthermore, little work has been done on the synthesis of Ruthenium-based TMD, even though it is the transition metal, when combined in oxides, with the best performance as pseudocapacitive material $[9,24]$. In practice, Ruthenium-based $\mathrm{TMD}$, and especially $\mathrm{RuS}_{2}$, can be synthesized by energy and time-consuming processes [50-52]. More recently, greener routes have been developed based on hydrothermal synthesis. However, these processes are based on thiourea $[53,54]$, as Sulphur precursor, which is suspected of causing cancer in addition to be harmful for the user, as reported in the Safety Data Sheets (SDS). Thus, it is clear that L-cysteine, a natural amino acid which is already reported for the synthesis of $\mathrm{MoS}_{2}$ [55], can be attractive as a green precursor of Sulphur and, for this reason, it has been used in this work. Moreover, to the best of the authors' knowledge, no work has previously been done on the synthesis of hybrid materials containing $\mathrm{RuS}_{2}$. Thus, the novelty of this work deals with the filling of the gap of literature in this field.

This paper focuses on the synthesis of a new hybrid material for electrodes in supercapacitor applications by hydrothermal synthesis. Starting from an aqueous dispersion of graphene oxide (GO), a precursor of Ruthenium $\left(\mathrm{RuCl}_{3}\right)$ and L-cysteine as the precursor of Sulphur, we demonstrate an easy way to obtain an aerogel of reduced graphene oxide (RGO) decorated with Ruthenium active species containing Ruthenium Sulfide $\left(\mathrm{RuS}_{2}\right)$. This TMD is able to enhance the specific capacitance by Faradaic processes thanks to its structural properties. As this hybrid material has never been synthesized before, a full characterization was required. For this purpose, we performed a careful examination by Field Emission Scanning Electron Microscopy (FESEM), Transmission Electron Microcopy (TEM), Energy-Dispersive X-ray spectroscopy (EDX), X-ray Diffraction (XRD), X-ray Photoelectron Specteoscopy (XPS) and micro-Raman, in addition to electrochemical characterization in planar configuration carried out by Cyclic Voltammetry and Galvanostatic Charge/Discharge measurements.

\section{Results and Discussion}

\subsection{Characterization of Morphology and Structure}

The morphology of a typical aerogel sample is presented in Figure 1. It is clear from low magnification images (See Figure 1a) that the sample exhibits a three-dimensional structure of interconnected RGO flakes, which forms during the hydrothermal treatment, in accordance with results previously reported in literature [56]. The slightly wrinkled flakes have lateral size of micrometer order and they are decorated with nanostructures. High resolution images (See Figure 1b) show that these nanostructures are almost spherical (with diameter in the 5-50 $\mathrm{nm}$ range) and they are distributed in sub-micrometer agglomerates inside the aerogel. EDX analysis (shown in the Supporting 
Information) was used as preliminary confirmation of the successful synthesis of Ruthenium active species nanostructures: in fact, the detected elements are $\mathrm{C}, \mathrm{O}, \mathrm{Ru}, \mathrm{S}$ and $\mathrm{Cl}$. The presence of $\mathrm{Cl}$ is due to the $\mathrm{RuCl}_{3}$ synthesis precursor unreacted and physisorbed on the surface.
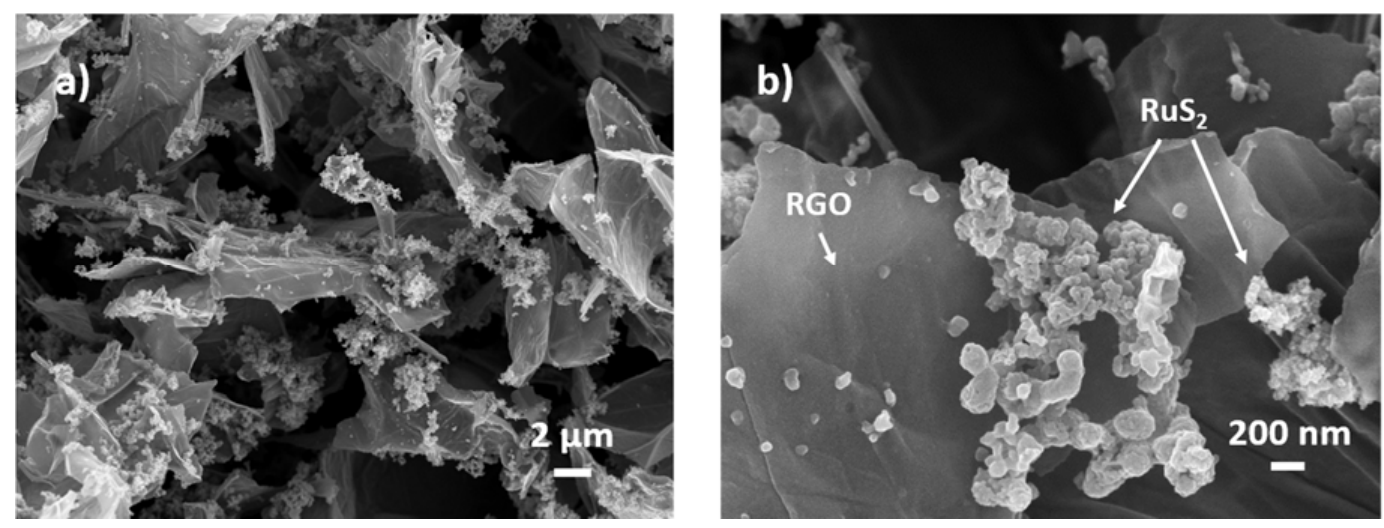

Figure 1. Low-magnification (a) and high magnification (b) FESEM images of RGO aerogel decorated with Ruthenium active species containing $\mathrm{RuS}_{2}$ nanostructures.

The overall morphology of the aerogel is promising for supercapacitor application: in fact, the porous 3D structure leads to facile impregnation with the electrolyte. Moreover, the successful decoration of the RGO flakes with Ruthenium active species, and in particular $\mathrm{RuS}_{2}$ nanoparticles, can in principle boost the capacitance of the electrode through Faradaic reactions at the surface of the nanoparticles. A more refined overview of the chemical composition of the material was obtained by XPS spectroscopy (Caltech, Pasadena, CA, USA). It is well known that this spectroscopy technique allows for the investigation of the chemical state of detected elements and therefore it is often performed for chemical phase identification [57]. Moreover, since the sampling depth of XPS is $<10 \mathrm{~nm}$, this technique is particularly well-suited for the analysis of materials in view of their application in devices that rely on surface effects.

At first, a survey spectrum (see Supplementary Information) was acquired, confirming the presence of the chemical elements previously outlined by EDX and highlighting traces of $\mathrm{N}$ as probable elemental residue in the starting commercial GO flakes, as a consequence of the oxidation process of graphite. High Resolution (HR) scans of the most significant regions of the photoelectron spectrum were acquired and they are shown in Figure 2a,b. Concerning carbon, the dominant contribution to the $\mathrm{C} 1 \mathrm{~s} / \mathrm{Ru} 3 \mathrm{~d}$ region of the $\mathrm{C}-\mathrm{C}$ peak at $284.8 \mathrm{eV}$ with respect to peaks associated to carbon-oxygen bonds proves the successful reduction of GO. Regarding the Ru3d doublet, the positions of the two peaks $(280.8 \mathrm{eV}, 285.0 \mathrm{eV})$ are compatible with $\mathrm{RuS}_{2}$ phase, according to the literature [53,58]. Further confirmation of the presence of $\mathrm{RuS}_{2}$ is provided by the Ru3p $3 / 2$ peak $(462.4 \mathrm{eV}$, shown in Supporting Information) and by the S2p doublet $(162.5 \mathrm{eV}, 163.7 \mathrm{eV})$, which all approximately agree with previous XPS analyses [59]. The S2p region is characterized by two more doublets at higher binding energies, which can be related to elemental Sulphur [60] and sulphites/sulphates [61]. As previously stated, both EDX and XPS survey analysis point to the presence of Chlorine, which was attributed to a residue of the $\mathrm{RuCl}_{3}$ precursor. Further confirmation is given by the deconvolution of the $\mathrm{Cl} 2 \mathrm{p}$ region of the photoelectron spectrum (Supporting Information), with binding energies $\left(\mathrm{Cl}_{2} \mathrm{p}_{3 / 2}=197.9 \mathrm{eV}\right.$, $\mathrm{Cl} 2 \mathrm{p}_{1 / 2}=199.5 \mathrm{eV}$ ), which, according to the literature [62], can be possibly ascribed to $\mathrm{RuCl}_{3}$, although it has been recently proposed that this doublet can be assigned to $\mathrm{HCl}$ [63].

It was possible to calculate relative atomic concentration values for $\mathrm{Ru}, \mathrm{S}$ and $\mathrm{Cl}$ from Ru3 $\mathrm{p}_{3 / 2}$, $\mathrm{S} 2 \mathrm{p}$ and $\mathrm{Cl} 2 \mathrm{p}$ regions, respectively. The $\mathrm{Ru} 3 \mathrm{p}_{3 / 2}$ region was chosen for $\mathrm{Ru}$ since it does not overlap with other elements. It is interesting to note that the atomic concentration ratio $\mathrm{S} / \mathrm{Ru}$ is 2.25 , while when we consider just the S2p doublet assigned to $\mathrm{RuS}_{2}$ phase, the ratio is $\mathrm{S}_{\mathrm{RuS} 2} / \mathrm{Ru} \approx 1.85$. These results provide proof that $\mathrm{RuS}_{2}$ phase is obtained in the Ruthenium active species, with acceptable 
stoichiometry. Finally, it must be stressed that the $\mathrm{Cl} / \mathrm{Ru}$ ratio is 0.08 , therefore making the $\mathrm{RuCl}_{3}$ residue concentration negligible with respect to the dominant $\mathrm{RuS}_{2}$ phase.
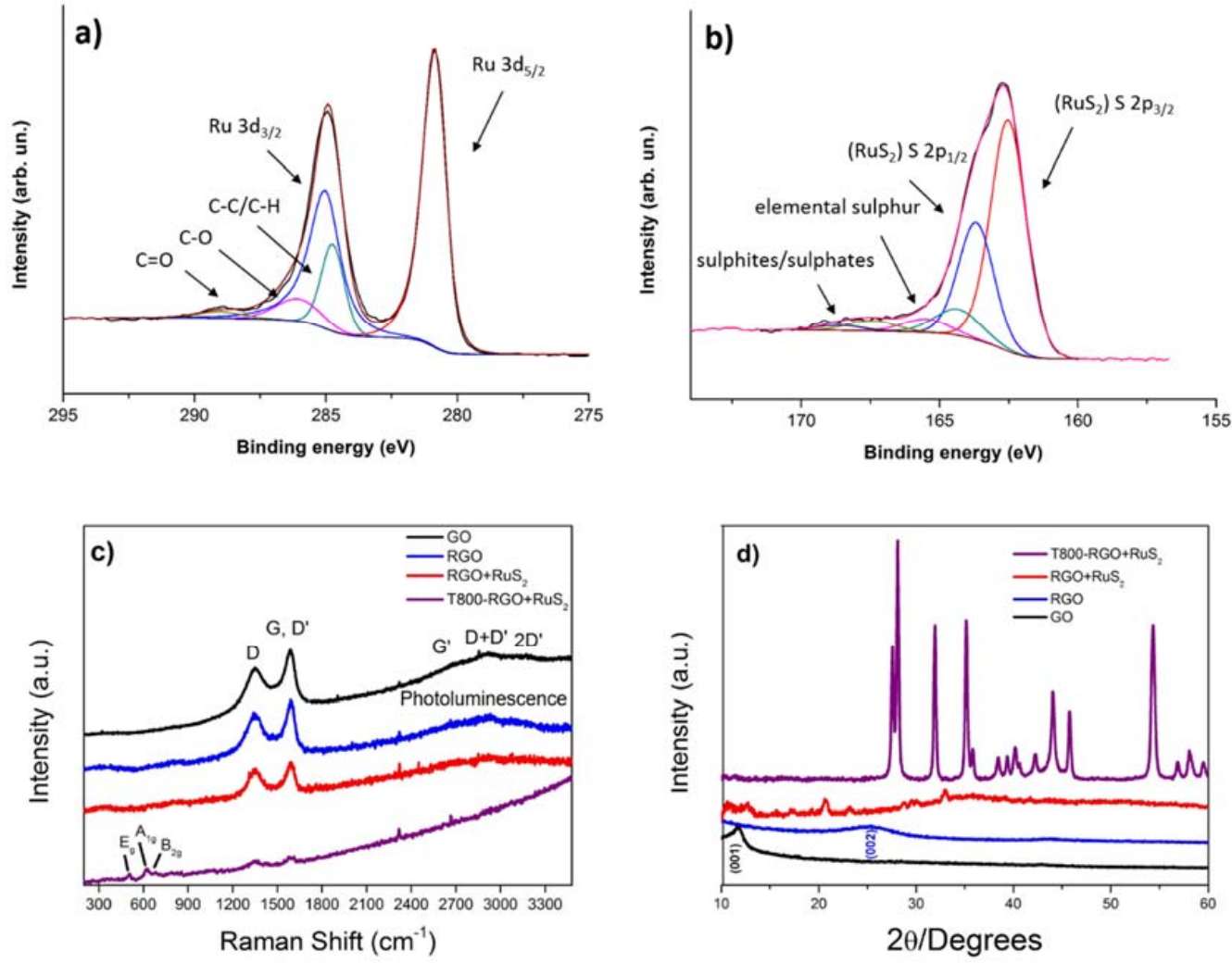

Figure 2. XPS High resolution scans of (a) C1s/Ru3d and (b) S2p regions of RGO aerogel decorated with Ruthenium active species containing $\mathrm{RuS}_{2}$ nanoparticles; (c) Raman spectra of pristine GO, RGO, RGO/Ruthenium active species (before and after thermal annealing in inert gas) aerogels; (d) XRD of pristine GO, RGO and as-synthesized $\mathrm{RGO} / \mathrm{RuS}_{2}$ (before and after thermal annealing in inert gas).

Raman spectra, reported in Figure 2c, depicts how the hydrothermal process is efficient in the reduction of the pristine GO to RGO even in the presence of the Ru and S precursors, as demonstrated by the increase of the $\mathrm{I}_{\mathrm{D}} / \mathrm{I}_{\mathrm{G}}$ ratio (from 0.78 to 0.98 ) that suggests the formation of more $\mathrm{sp}^{2}$ domains [64] and the decrease of photoluminescence ascribed in graphene oxide to band-gap emission from electron-confined $\mathrm{sp}^{2}$ islands and to oxygen-related defect states [65]. In addition to the typical Raman peaks of RGO [65], for the RGO/Ruthenium active species hybrid aerogel, a slight broadening of the $G$ peak at $1589 \mathrm{~cm}^{-1}$ is observed together with a loss of bands resolution in the $2600-3200 \mathrm{~cm}^{-1}$ range, maybe due to interference phenomena, in $\mathrm{sp}^{2}$ cluster stacking, because of the formation of $\mathrm{RuS}_{2}$ structures. Unfortunately, the related spectrum (red line) does not give evidence of vibrational modes assignable to Ru-S containing species, as expected in the $350-450 \mathrm{~cm}^{-1}$ range [66]. Only when the aerogel is annealed at $800{ }^{\circ} \mathrm{C}$, for $2 \mathrm{~h}$, under inert gas flux, it is possible to single out (purple line) at 504, 615 and $685 \mathrm{~cm}^{-1}$ the three $\mathrm{RuO}_{2}$ main features assigned to $\mathrm{E}_{\mathrm{g}}, \mathrm{A}_{1 \mathrm{~g}}$ and $\mathrm{B}_{2 \mathrm{~g}}$ modes, respectively [67]. This result is in accordance with XRD characterization (discussed in the following), so confirming that the $\mathrm{RuS}_{2}$ contained in the hybrid aerogel is scarcely crystalline, and, only thanks to the annealing process, it is possible to obtain a crystalline, but unstable, material that, in contact with atmospheric oxygen, tends to oxidize. As Raman spectroscopy is a surface investigation technique, the effect of environmental oxidation is more evident than for X-ray Diffraction, which is a bulk investigation technique.

Figure $2 \mathrm{~d}$ reports the XRD pattern on the RGO/Ruthenium active species (containing $\mathrm{RuS}_{2}$ nanoparticles sample) synthesized by hydrothermal method. The diffraction peaks are very weak, 
indicating that both $\mathrm{RGO}$ and $\mathrm{RuS}_{2}$ arrange in short range ordered structure. This fact was already observed for $\mathrm{MoS}_{2}$ flakes [46,55]. Moreover, the amorphous (quite disordered) structure of the Ruthenium Sulphide is due to the low temperature process. Indeed, the Ruthenium Sulphide starts to crystallize at a temperature of $650{ }^{\circ} \mathrm{C}$ as reported previously [54]. Nevertheless, the three peaks with the higher intensity (red line) correspond to the elemental Sulphur $\left(20.47^{\circ}\right.$ and $\left.22.97^{\circ}\right)$ and $\mathrm{RuS}_{2}\left(32.73^{\circ}\right)$, respectively. In addition, all of the other peaks match with the ones of the reference spectra of $\mathrm{RuS}_{2}$ (JCPDS card $\mathrm{N}^{\circ} 00-019-1107$ ); $\mathrm{RuO}_{2}$ (JCPDS card N00-040-1290); Ru (JCPDS card $\mathrm{N}^{\circ}$ 00-006-0663); $\mathrm{RuCl}_{3}$ (JCPDS card $\mathrm{N}^{\circ} 00-036-1225$ ) and $\mathrm{S}$ (JCPDS card $\mathrm{N}^{\circ} 00-023-0562$ ). In order to increase the crystallinity, an annealing in inert atmosphere for $2 \mathrm{~h}$ at $800{ }^{\circ} \mathrm{C}$ was carried out. The XRD pattern of the annealed sample (purple line) is reported in Figure $2 \mathrm{~d}$. The crystallinity has been increased by the annealing process. All of the typical peaks of the Ruthenium Sulphide are displayed and confirm the presence of the dichalcogenide structures in the as-prepared material synthesized by hydrothermal method. However, peaks corresponding to $\mathrm{RuO}_{2}$ and $\mathrm{Ru}$ can also be observed. Furthermore, the disappearance of $\mathrm{RuCl}_{3}$ and $\mathrm{S}$ can be attributed to a desorption of the unreacted species on the surface of the hybrid material.

TEM (FEI, Hillsboro, OR, USA) characterization was conducted on the aerogel in order to reach deeper insight into the morphology and crystalline structure of the sample. Figure 3a shows a low magnification bright field image of a typical RGO flake decorated with $\mathrm{RuS}_{2}$ nanostructures, which are clearly visible as low-intensity features due to mass contrast. A selected area electron diffraction (SAED) pattern of a clear region of the RGO flake (Figure 3b) confirms the characteristic in-plane hexagonal ordering of carbon atoms typical of graphene. This is a further indication that the reduction process under hydrothermal treatment allows for good in-plane arrangement of carbon atoms. This spatial configuration assures a good electrical conductivity between the 3D structures of interconnected RGO. On the other hand, SAED patterns obtained on agglomerates of $\mathrm{RuS}_{2}$ nanoparticles (Figure 3c) suggest amorphicity, or at least low crystalline quality. This is further confirmed by high resolution images (such as Figure 3d), where no lattice fringes are visible.
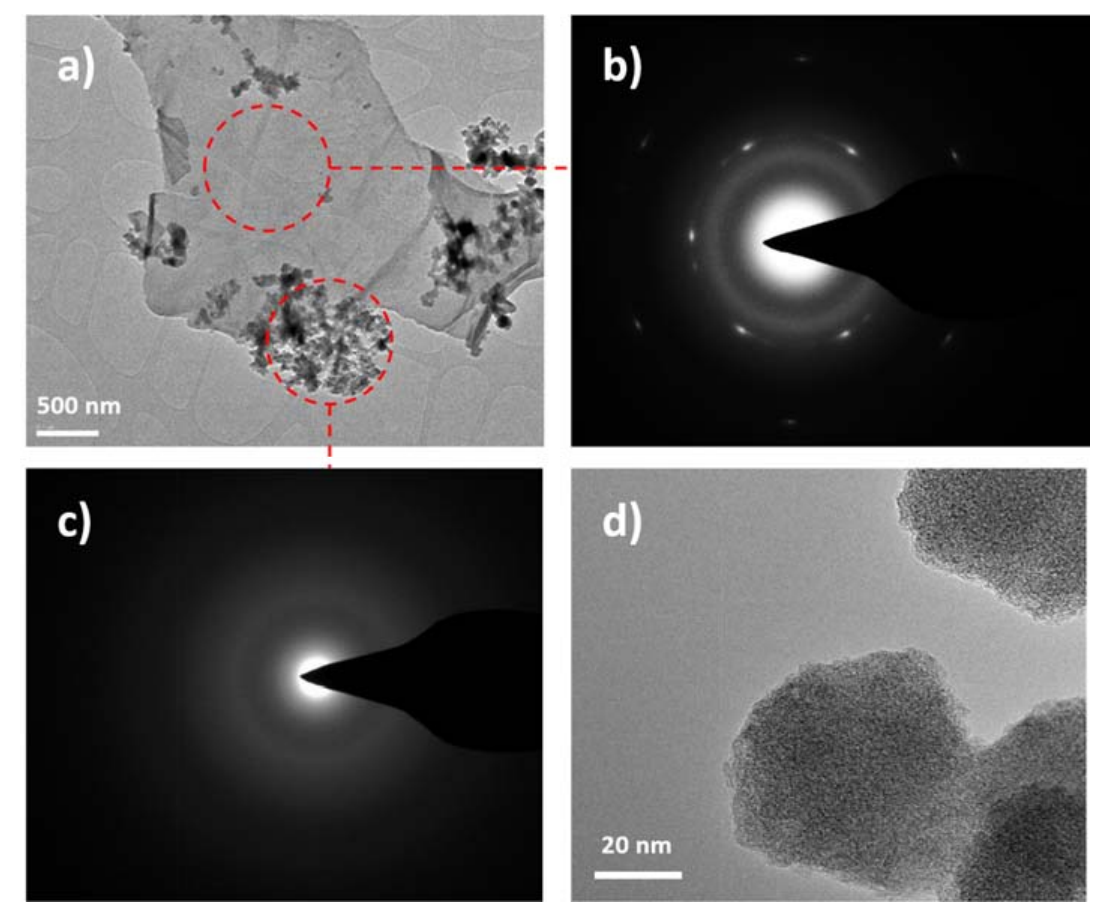

Figure 3. (a) low-magnification Bright Field TEM image of RGO flake decorated with Ruthenium active species nanoparticles. SAED pattern of RGO flake (b) and Ruthenium active species nanoparticles (c); High Resolution TEM image of Ruthenium active species nanoparticle (d). 


\subsection{Electrochemical Performance}

Hybrid materials synthesized by using the hydrothermal method were investigated by Cyclic Voltammetry $(\mathrm{CV})$ in a two-electrode configuration and a potential window of $2 \mathrm{~V}$. Results obtained at different scan rates are shown in Figure 4a. The box-like voltammogram indicates a typical double layer capacitor behavior. The signals due to pseudo-capacitance derived from oxygen-containing functional group are weak, which is in perfect agreement with XPS and Raman analyses. In addition, the pseudo-capacitance effects related to the Ruthenium active species, and in particular $\mathrm{RuS}_{2}$, in addition to nanostructures are not clearly distinguishable probably due to the low concentration in the hybrid. The evolution of the Specific Capacitance as a function of the scan rate is reported on Figure $4 \mathrm{~b}$. The storage ability of the hybrid is almost five times higher than the one observed for pure RGO (191 vs. 33 F/g [46], at $10 \mathrm{mV} / \mathrm{s}$ ). Moreover, the highest RGO/Ruthenium active species Specific Capacitance was obtained at $5 \mathrm{mV} / \mathrm{s}$ and corresponds to a value of $238 \mathrm{~F} / \mathrm{g}$. This result is remarkable for a green one-pot hydrothermal synthesis.

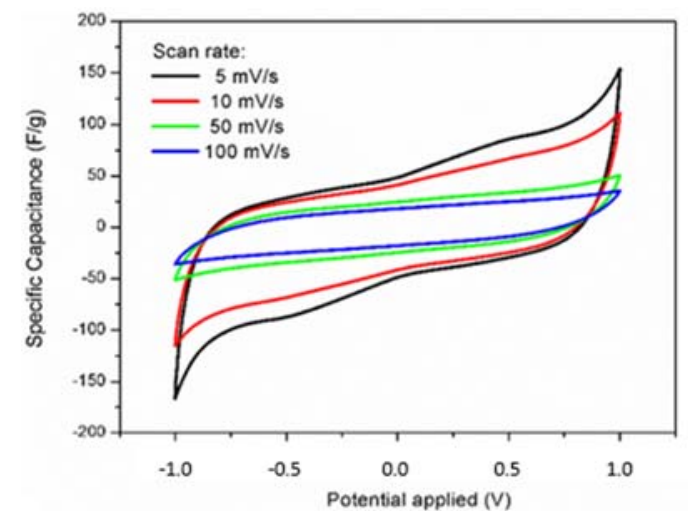

(a)

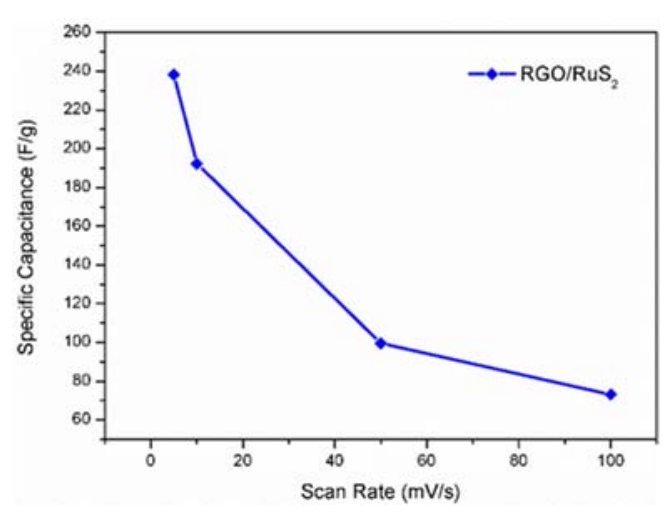

(b)

Figure 4. (a) cyclic Voltammograms of RGO/Ruthenium active species hybrid at different scan rate; (b) evolution of the Specific Capacitance with the scan rate.

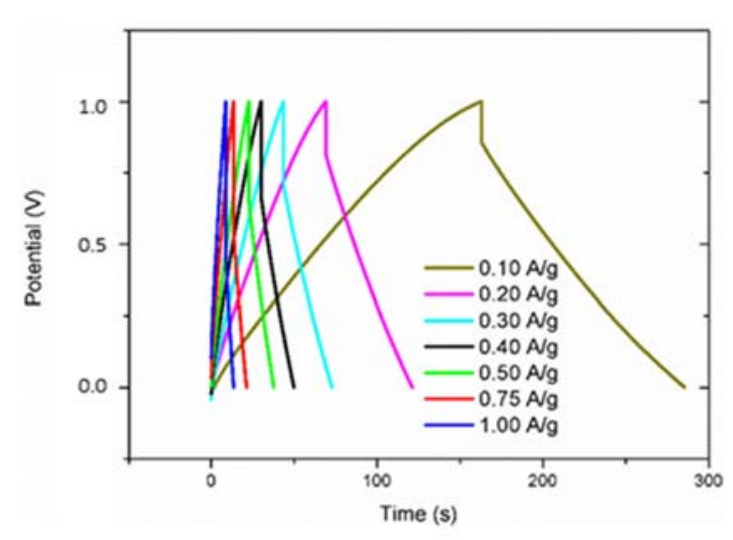

(a)

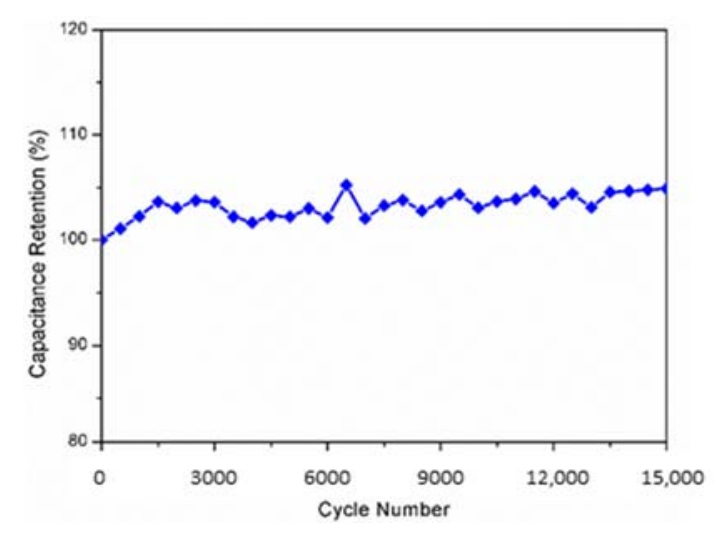

(b)

Figure 5. (a) charge-discharge curves at different current density and (b) evolution of the capacitance retention in function of the cycle number for the RGO/Ruthenium active species hybrid.

Galvanostatic Charge/Discharge measurements were performed on the hybrid sample (see Figure 5a). The potential window was reduced to $1 \mathrm{~V}$ to avoid the water splitting effects. Galvanostatic charge-discharge curves reveal that all the materials own good capacitive behavior due to the linearity 
of the chronopotentiograms. The ohmic resistance (depicted by the voltage drop (IR drop) in curves of Figure 5a) is probably due to the presence of sulphites/sulphates $\left(\mathrm{SO}_{\mathrm{x}}\right)$ species. Finally, and very interestingly, $\mathrm{RGO} /$ Ruthenium active species hybrid materials demonstrate a perfect stability after 15,000 cycles (see Figure $5 b$ ). Indeed, it is possible to observe a steady increase in capacitance (about the $5 \%$ ) for the hybrid. As reported in our previous work, the reference (RGO) has a lower stability with almost $95 \%$ of the capacitance retained after the same number of cycles [46]. The higher stability of the hybrid material is the result of a surface activation effect [68] and an increased porosity of the carbonaceous matrix that allows rapid diffusion of the electrolyte through the porous structure [69].

\section{Materials and Methods}

\subsection{Materials}

Graphene Oxide (Single Layer, thickness: $0.7-1.2 \mathrm{~nm}$, purity $99 \mathrm{wt} \%$ ) was purchased from Cheaptubes (Cambridgeport, VT, USA). L-cysteine used as precursor of Sulphur and $\mathrm{RuCl}_{3}$ used as precursor of Ruthenium were purchased from Sigma Aldrich (Milano, Italy) and Alfa Aesar (Heysham, UK), respectively. $\mathrm{NaCl}$ (anhydrous, ACS reagent, purity $\geq 99.9 \%$, Sigma Aldrich, Milano, Italy) was used as electrolyte. Poly(vinylidene fluoride) was used as binder after dispersion in Dimethyl Sulfoxide (DMSO, purity $\geq 99.5 \%$ (GC), Sigma (Milano, Italy)) Carbon Black (purity $\geq 99.9 \%$, Alfa Aesar (Heysham, UK)) was used as conductive material in the electrode fabrication. All products were used without purification.

\subsection{Preparation of $R G O, R G O /$ Ruthenium Active Species Aerogels}

Graphene oxide (GO) was dispersed in de-ionized water $(2 \mathrm{mg} / \mathrm{mL}$ for $17 \mathrm{~mL}$ total volume) at room temperature and sonicated for $30 \mathrm{~min}$. After sonication, the brown solution was transferred in a Teflon lined stainless steel autoclave with total volume of $26 \mathrm{~mL}$ and heated at a temperature of $180^{\circ} \mathrm{C}$ for $12 \mathrm{~h}$, in a muffle furnace. After the hydrothermal reaction, the autoclave was cooled naturally until room temperature. Then, the black hydrogel obtained was rapidly frozen using liquid nitrogen and dried overnight under vacuum to obtain the reduced graphene oxide (RGO) aerogel. For the $\mathrm{RGO} /$ Ruthenium active species sample, $132.8 \mathrm{mg}$ of $\mathrm{RuCl}_{3}$ as Ruthenium precursor and $61.5 \mathrm{mg}$ of $\mathrm{L}$-cysteine were added to the $\mathrm{GO}$ in order to obtain a $\mathrm{Ru} / \mathrm{S}$ atomic ratio equal to $1 / 3$. Materials were dispersed in de-ionized water at room temperature and the same procedure used for RGO aerogel was repeated.

\subsection{Materials Characterizations}

The morphology and composition of the synthesized products were characterized before the tests in supercapacitor configuration.

The morphology of the aerogel samples was characterized by means of Field Emission Scanning Electron Microscopy (FESEM) with a Zeiss Supra 40 microscope (Zeiss, Milano, Italy) equipped with a Oxford Instruments $10 \mathrm{~mm}^{2} \mathrm{Si}(\mathrm{Li})$ Energy Dispersive X-ray (EDX) spectrometer (X-Max ${ }^{\mathrm{N}}$, Abingdon-on-Thames, UK) for elemental analysis.

The crystallinity of the hybrid material was evaluated by X-ray Diffraction by using a PANalytical $X^{\prime}$ Pert Powder (Cu K $\alpha$ radiation, Lissone, Italy); $2 \theta$ range: 10-80; $2 \theta$ step: 0.028; step time: 2 s, with fixed specimen and moving $\mathrm{X}$-ray source and detector simultaneously of a $\theta$ angle.

Raman spectroscopy on aerogels were performed in order to study the extent of reduction of $\mathrm{GO}$ and the effect of hybrid composition on the samples vibrational features. Hybrid materials were characterized, in backscattering light collection through a microscope objective (50X) by means of a Renishaw InVia Reflex micro-Raman spectrometer (Renishaw plc, Sheffield, UK), equipped with a cooled charge-coupled device (CCD) camera and a $514.5 \mathrm{~nm}$ diode laser (selected excitation wavelength). Each spectrum was collected after gently pressing the aerogel powder on a microscope glass slide, with the following parameters: $10 \mathrm{~mW}$ laser power, $10 \mathrm{~s}$ of exposure time and 1 accumulation. 
Further insight into the morphology and crystalline structure of the samples was obtained by Transmission Electron Microscopy (TEM), using an FEI Tecnai G2 F20 S-TWIN instrument (FEI, Hillsboro, OR, USA) operated at $200 \mathrm{kV}$ acceleration voltage. Concerning sample preparation for TEM analysis, a drop of aerogel dispersion in ethanol was deposited on a holey carbon copper grid. Gatan Microscopy Suite software (GMS 3, Gaitan, Abingdon, UK) was used for the processing of high-resolution images and electron diffraction patterns.

The chemical composition was investigated with a PHI 5000 Versaprobe scanning X-ray photoelectron spectrometer (Phi, Roma, Italy) (monochromatic Al K-alpha X-ray source with $1486.6 \mathrm{eV}$ energy). Concerning the detection of the photoelectron signal, different pass energy values were employed: $187.85 \mathrm{eV}$ for survey spectra and $23.5 \mathrm{eV}$ for high-resolution peaks. Spectra were analyzed using MultiPak 9.6 (Phi, Roma, Italy) and CasaXPS softwares (Caltech, Pasadena, CA, USA). Charge neutralization during measurements was obtained with a combined electron and $\mathrm{Ar}^{+}$ion gun neutralizer system. All core-level peak energies were referenced to $\mathrm{C} 1 \mathrm{~s}$ peak at $284.8 \mathrm{eV}(\mathrm{C}-\mathrm{C} / \mathrm{C}-\mathrm{H}$ bonds) after fitting the $\mathrm{C} 1 \mathrm{~s} / \mathrm{Ru} 3 \mathrm{~d}$ region with suitable synthetic components. The background contribution in HR spectra was subtracted by means of a Shirley function [70].

\subsection{Electrodes Preparation}

For all the aerogel materials, the electrode slurry was composed by a ratio of active synthesized aerogel/carbon black/PVDF (Polyvinylidene Difluoride) equivalent to 15/1.5/1. PVDF was used as binder and carbon black was used to assure electrical contact between the flakes of RGO in the three-dimensional nanostructure.

\subsection{Supercapacitor Device and Electrochemical Measurements}

A thin film about $50 \mathrm{~nm}$ of Platinum was deposited by Direct Current sputtering on two microscopes slides. These glasses were used as current collectors. The devices were fabricated in symmetric electrodes configuration and were sealed by means of a thermoplastic thin film polymer. Clean room paper was used as separator. Electrolyte, $1 \mathrm{M} \mathrm{NaCl}$, was inserted in the dispositive by means of a depression created by a vacuum pump. The Cyclic voltammetry measurements were performed with a Metrohm Autolab PGSTAT128 potentiostat/galvanostat (Metrohm, Barendrecht, The Netherlands). Galvanostatic charge/discharge measurements were obtained with an Arbin Instrument Testing System model BT-2000 (Arbin Instruments, College Station, TX, USA). Both kinds of measurements were performed in device configuration (e.g., two symmetric electrodes).

\subsection{Calculation of Capacitance}

Specific capacitance for the supercapacitors was calculated from the cyclic voltammograms measurements according to the method established by Stoller and Ruoff for one electrode [71]:

In voltammetry, the capacitance is defined as the area under the current transient during one linear scan of the voltammogram normalized with respect to the employed potential window $(\Delta \mathrm{V})$, as:

$$
\mathrm{C}=\frac{\int_{\mathrm{t}_{1}}^{\mathrm{t}_{2}} \mathrm{i} \mathrm{dt}}{\Delta \mathrm{V}}
$$

The specific capacitance of one electrode can be estimated for a two-electrode cell and in device configuration by the following equation:

$$
\mathrm{C}_{\mathrm{S}}=4 \frac{\mathrm{C}}{\mathrm{m}_{1}+\mathrm{m}_{2}}
$$

where $\mathrm{m}_{1}$ and $\mathrm{m}_{2}$ are the masses of the first and the second electrodes and the multiplier of four adjusts the capacitance of the cell and the combined mass of two electrodes to the capacitance and mass of a single electrode. 


\section{Conclusions}

In this paper, we report an easy and green one-pot hydrothermal synthesis of an RGO/Ruthenium active species (containing $\mathrm{RuS}_{2}$ nanoparticles) hybrid for electrodes in supercapacitor applications. The synthesis is carried out in a Teflon lined stainless steel autoclave from Graphene Oxide, Ruthenium Chloride and L-cysteine, an amino acid, as Ruthenium and Sulphur precursor, respectively. The low temperature process $\left(180^{\circ} \mathrm{C}\right)$ allows for synthesizing Ruthenium active species containing $\mathrm{RuS}_{2}$ nanostructures supported on reduced graphene oxide flakes (RGO), for which interconnected porous structure is a key feature for electrodes in supercapacitor applications because of the promotion of electrolyte diffusion throughout the pores and, indeed, the increase of the electrode/electrolyte interface.

FESEM analysis displays a three-dimensional structure of interconnected RGO flakes decorated with nanostructures and XPS characterization confirms the $\mathrm{RuS}_{2}$ composition: the successful reduction of graphene oxide in RGO and the reached $\mathrm{RuS}_{2}$ proper stoichiometry. XRD patterns highlight that both $\mathrm{RGO}$ and $\mathrm{RuS}_{2}$ arrange in short range ordered structure, due to the $\mathrm{Ru} / \mathrm{S}$ precursors low ratio, chosen for the hydrothermal synthesis. After annealing in inert atmosphere, only, the observed diffraction peaks correspond to the Ruthenium active species containing $\mathrm{RuS}_{2}$ crystalline nanostructure. Moreover, Raman analysis confirms that Graphene Oxide is successfully reduced and TEM images display RGO crystalline flakes decorated with Ruthenium active species containing $\mathrm{RuS}_{2}$ amorphous nanostructures. The SAED (Selected Area Electron Diffraction) patterns show the characteristic in-plane hexagonal ordering of carbon atoms typical of graphene and the amorphous state or, at least, a poor crystallinity of $\mathrm{RuS}_{2}$ nanostructures.

Finally, by means of electrochemical characterization, a noticeable Specific Capacitance of $238 \mathrm{~F} / \mathrm{g}$, at $5 \mathrm{mV} / \mathrm{s}$, is reached by using the RGO/Ruthenium active species containing $\mathrm{RuS}_{2}$ nanoparticles hybrid as electrode material and a relevant stability, over 15,000 cycles (current density: $1 \mathrm{~A} / \mathrm{g}$ ), is obtained. These two achievements suggest that the hybrid structure exhibits the potentiality for exploitation as electrode component in supercapacitors.

Supplementary Materials: The following are available online at www.mdpi.com/1996-1944/11/1/57/s1. Representative EDX spectrum of RGO/Ruthenium active species sample, Figure S2: Survey spectrum of RGO sample decorated with $\mathrm{RuS}_{2}$ nanostructures, Figure S3: High-resolution XPS scans of the Ru3p $\mathrm{p}_{3 / 2}$ (a) and Cl2p (b) regions.

Acknowledgments: All sources of funding of the study should be disclosed. Please clearly indicate grants that you have received in support of your research work. Clearly state if you received funds for covering the costs to publish in open access.

Author Contributions: A.G. and P.R. conceived and designed the experiments; A.G. and M.F. performed the experiments; and all of the authors participated in the data analysis and manuscript preparation.

Conflicts of Interest: The authors declare no conflict of interest.

\section{References}

1. Winter, M.; Brodd, R.J. What are batteries, fuel cells, and supercapacitors? Chem. Rev. 2004, 104, 4245-4269. [CrossRef] [PubMed]

2. Yu, G.; Xie, X.; Pan, L.; Bao, Z.; Cui, Y. Hybrid nanostructured materials for high-performance electrochemical capacitors. Nano Energy 2013, 2, 213-234. [CrossRef]

3. Gu, W.; Yushin, G. Review of nanostructured carbon materials for electrochemical capacitor applications: Advantages and limitations of activated carbon, carbide-derived carbon, zeolite-templated carbon, carbon aerogels, carbon nanotubes, onion-like carbon, and graphene. Wiley Interdiscip. Rev. Energy Environ. 2014, 3, 424-473. [CrossRef]

4. Pekala, R.W.; Farmer, J.C.; Alviso, C.T.; Tran, T.D.; Mayer, S.T.; Miller, J.M.; Dunn, B. Carbon aerogels for electrochemical applications. J. Non-Cryst. Solids 1998, 225, 74-80. [CrossRef]

5. Mahmood, N.; Zhang, C.; Yin, H.; Hou, Y. Graphene-based nanocomposites for energy storage and conversion in lithium batteries, supercapacitors and fuel cells. J. Mater. Chem. A 2014, 2, 15-32. [CrossRef] 
6. Zhang, L.L.; Zhao, X.S. Carbon-based materials as supercapacitor electrodes. Chem. Soc. Rev. 2009, $38,2520$. [CrossRef] [PubMed]

7. Nardecchia, S.; Carriazo, D.; Ferrer, M.L.; Gutiérrez, M.C.; del Monte, F. Three dimensional macroporous architectures and aerogels built of carbon nanotubes and/or graphene: Synthesis and applications. Chem. Soc. Rev. 2013, 42, 794-830. [CrossRef] [PubMed]

8. Simon, P.; Gogotsi, Y. Materials for electrochemical capacitors. Nat. Mater. 2008, 7, 845-854. [CrossRef] [PubMed]

9. Wu, Z.S.; Wang, D.W.; Ren, W.; Zhao, J.; Zhou, G.; Li, F.; Cheng, H.M. Anchoring hydrous $\mathrm{RuO}_{2}$ on graphene sheets for high-performance electrochemical capacitors. Adv. Funct. Mater. 2010, 20, 3595-3602. [CrossRef]

10. Ahn, Y.R.; Song, M.Y.; Jo, S.M.; Park, C.R.; Kim, D.Y. Electrochemical capacitors based on electrodeposited ruthenium oxide on nanofibre substrates. Nanotechnology 2006, 17, 2865-2869. [CrossRef]

11. Patake, V.D.; Lokhande, C.D.; Joo, O.S. Electrodeposited ruthenium oxide thin films for supercapacitor: Effect of surface treatments. Appl. Surf. Sci. 2009, 255, 4192-4196. [CrossRef]

12. Kim, I.-H.; Kim, K.-B. Electrochemical Characterization of Hydrous Ruthenium Oxide Thin-Film Electrodes for Electrochemical Capacitor Applications. J. Electrochem. Soc. 2006, 153, A383. [CrossRef]

13. Arabale, G.; Wagh, D.; Kulkarni, M.; Mulla, I.S.; Vernekar, S.P.; Vijayamohanan, K.; Rao, A.M. Enhanced supercapacitance of multiwalled carbon nanotubes functionalized with ruthenium oxide. Chem. Phys. Lett. 2003, 376, 207-213. [CrossRef]

14. Jiang, J.; Kucernak, A. Electrochemical supercapacitor material based on manganese oxide: Preparation and characterization. Electrochim. Acta 2002, 47, 2381-2386. [CrossRef]

15. Wu, M.-S.; Julia Chiang, P.-C. Fabrication of Nanostructured Manganese Oxide Electrodes for Electrochemical Capacitors. Electrochem. Solid-State Lett. 2004, 7, A123. [CrossRef]

16. Subramanian, V.; Zhu, H.; Wei, B. Nanostructured $\mathrm{MnO}_{2}$ : Hydrothermal synthesis and electrochemical properties as a supercapacitor electrode material. J. Power Sources 2006, 159, 361-364. [CrossRef]

17. Kandalkar, S.G.; Gunjakar, J.L.; Lokhande, C.D. Preparation of cobalt oxide thin films and its use in supercapacitor application. Appl. Surf. Sci. 2008, 254, 5540-5544. [CrossRef]

18. Patil, U.M.; Salunkhe, R.R.; Gurav, K.V.; Lokhande, C.D. Chemically deposited nanocrystalline NiO thin films for supercapacitor application. Appl. Surf. Sci. 2008, 255, 2603-2607. [CrossRef]

19. Hwang, S.-W.; Hyun, S.-H. Synthesis and characterization of tin oxide/carbon aerogel composite electrodes for electrochemical supercapacitors. J. Power Sources 2007, 172, 451-459. [CrossRef]

20. Yan, Y.; Li, B.; Guo, W.; Pang, H.; Xue, H. Vanadium based materials as electrode materials for high performance supercapacitors. J. Power Sources 2016, 329, 148-169. [CrossRef]

21. Da Silva, D.L.; Delatorre, R.G.; Pattanaik, G.; Zangari, G.; Figueiredo, W.; Blum, R.-P.; Niehus, H.; Pasa, A.A. Electrochemical Synthesis of Vanadium Oxide Nanofibers. J. Electrochem. Soc. 2008, 155, E14. [CrossRef]

22. Hu, C.C.; Huang, C.M.; Chang, K.H. Anodic deposition of porous vanadium oxide network with high power characteristics for pseudocapacitors. J. Power Sources 2008, 185, 1594-1597. [CrossRef]

23. Mitchell, E.; Jimenez, A.; Gupta, R.K.; Gupta, B.K.; Ramasamy, K.; Shahabuddin, M.; Mishra, S.R. Ultrathin porous hierarchically textured $\mathrm{NiCO}_{2} \mathrm{O}_{4}$-graphene oxide flexible nanosheets for high-performance supercapacitors. New J. Chem. 2015, 39, 2181-2187. [CrossRef]

24. Lin, N.; Tian, J.; Shan, Z.; Chen, K.; Liao, W. Hydrothermal synthesis of hydrous ruthenium oxide/graphene sheets for high-performance supercapacitors. Electrochim. Acta 2013, 99, 219-224. [CrossRef]

25. Mitchell, E.; Candler, J.; de Souza, F.; Gupta, R.K.; Gupta, B.K.; Dong, L.F. High performance supercapacitor based on multilayer of polyaniline and graphene oxide. Synth. Met. 2015, 199, 214-218. [CrossRef]

26. Ye, S.; Feng, J.; Wu, P. Deposition of three-dimensional graphene aerogel on nickel foam as a binder-free supercapacitor electrode. ACS Appl. Mater. Interfaces 2013, 5, 7122-7129. [CrossRef] [PubMed]

27. Tingting, Y.; Ruiyi, L.; Zaijun, L.; Zhiguo, G.; Guangli, W.; Junkang, L. Hybrid of $\mathrm{NiCo}_{2} \mathrm{~S}_{4}$ and nitrogen and sulphur-functionalized multiple graphene aerogel for application in supercapacitors and oxygen reduction with significant electrochemical synergy. Electrochim. Acta 2016, 211, 59-70. [CrossRef]

28. Liang, M.; Liu, X.; Li, W.; Wang, Q. A Tough Nanocomposite Aerogel of Manganese Oxide and Polyaniline as an Electrode for a Supercapacitor. Chempluschem 2016, 81, 40-43. [CrossRef]

29. Huang, K.-J.; Wang, L.; Zhang, J.-Z.; Xing, K. Synthesis of molybdenum disulfide/carbon aerogel composites for supercapacitors electrode material application. J. Electroanal. Chem. 2015, 752, 33-40. [CrossRef] 
30. Yang, M.; Jeong, J.-M.; Huh, Y.S.; Choi, B.G. High-performance supercapacitor based on three-dimensional $\mathrm{MoS}_{2}$ /graphene aerogel composites. Compos. Sci. Technol. 2015, 121, 123-128. [CrossRef]

31. Hao, P.; Zhao, Z.; Li, L.; Tuan, C.-C.; Li, H.; Sang, Y.; Jiang, H.; Wong, C.P.; Liu, H. The hybrid nanostructure of $\mathrm{MnCo} 2 \mathrm{O} 4.5$ nanoneedle/carbon aerogel for symmetric supercapacitors with high energy density. Nanoscale 2015, 7, 14401-14412. [CrossRef] [PubMed]

32. Chhowalla, M.; Shin, H.S.; Eda, G.; Li, L.-J.; Loh, K.P.; Zhang, H. The chemistry of two-dimensional layered transition metal dichalcogenide nanosheets. Nat. Chem. 2013, 5, 263-275. [CrossRef] [PubMed]

33. Tan, C.; Zhang, H. Two-dimensional transition metal dichalcogenide nanosheet-based composites. Chem. Soc. Rev. 2015, 44, 2713-2731. [CrossRef] [PubMed]

34. Zhang, G.; Liu, H.; Qu, J.; Li, J. Two-dimensional layered $\mathrm{MoS}_{2}$ : Rational design, properties and electrochemical applications. Energy Environ. Sci. 2016, 9, 1190-1209. [CrossRef]

35. Choudhary, N.; Patel, M.D.; Park, J.; Sirota, B.; Choi, W. Synthesis of large scale $\mathrm{MoS}_{2}$ for electronics and energy applications. J. Mater. Res. 2016, 31, 824-831. [CrossRef]

36. Ramakrishna Matte, H.S.S.; Gomathi, A.; Manna, A.K.; Late, D.J.; Datta, R.; Pati, S.K.; Rao, C.N.R. MoS 2 and $\mathrm{WS}_{2}$ Analogues of Graphene. Angew. Chem. 2010, 122, 4153-4156. [CrossRef]

37. Wang, H.; Kong, D.; Johanes, P.; Cha, J.J.; Zheng, G.; Yan, K.; Liu, N.; Cui, Y. MoSe 2 and WSe 2 Nanofilms $^{2}$ with Vertically Aligned Molecular Layers on Curved and Rough Surfaces. Nano Lett. 2013, 13, 3426-3433. [CrossRef] [PubMed]

38. Kong, D.; Wang, H.; Cha, J.J.; Pasta, M.; Koski, K.J.; Yao, J.; Cui, Y. Synthesis of $\mathrm{MoS}_{2}$ and MoSe 2 Films with Vertically Aligned Layers. Nano Lett. 2013, 13, 1341-1347. [CrossRef] [PubMed]

39. Chen, J.; Tao, Z.-L.; Li, S.-L. Lithium Intercalation in Open-Ended TiS 2 Nanotubes. Angew. Chem. 2003, 115, 2197-2201. [CrossRef]

40. Tao, Z.-L.; Xu, L.-N.; Gou, X.-L.; Chen, J.; Yuan, H.-T. TiS 2 nanotubes as the cathode materials of Mg-ion batteries. Chem. Commun. (Camb.) 2004, 407, 2080-2081. [CrossRef] [PubMed]

41. Voiry, D.; Yamaguchi, H.; Li, J.; Silva, R.; Alves, D.C.B.; Fujita, T.; Chen, M.; Asefa, T.; Shenoy, V.B.; Eda, G.; et al. Enhanced catalytic activity in strained chemically exfoliated $\mathrm{WS}_{2}$ nanosheets for hydrogen evolution. Nat. Mater. 2013, 12, 850-855. [CrossRef] [PubMed]

42. Li, H.; Wu, J.; Yin, Z.; Zhang, H. Preparation and Applications of Mechanically Exfoliated Single-Layer and Multilayer $\mathrm{MoS}_{2}$ and WSe 2 Nanosheets. Acc. Chem. Res. 2014, 47, 1067-1075. [CrossRef] [PubMed]

43. Acerce, M.; Voiry, D.; Chhowalla, M. Metallic $1 \mathrm{~T}$ phase $\mathrm{MoS}_{2}$ nanosheets as supercapacitor electrode materials. Nat. Nanotechnol. 2015, 10, 313-318. [CrossRef] [PubMed]

44. Thangappan, R.; Kalaiselvam, S.; Elayaperumal, A.; Jayavel, R.; Arivanandhan, M.; Karthikeyan, R.; Hayakawa, Y. Graphene decorated with $\mathrm{MoS}_{2}$ nanosheets: A synergetic energy storage composite electrode for supercapacitor applications. Dalton Trans. 2016, 45, 2637-2646. [CrossRef] [PubMed]

45. Tang, J.; Jin, M.; Yuan, P.; Fu, Y.; Ma, X. Large-Area, Ultrathin Inorganic Network Coverages-Graphene Hierarchical Electrodes for Flexible, Heat-Resistant Energy Storage Application. Adv. Energy Mater. 2016, 6, 1600146. [CrossRef]

46. Gigot, A.; Fontana, M.; Serrapede, M.; Castellino, M.; Bianco, S.; Armandi, M.; Bonelli, B.; Pirri, C.F.; Tresso, E.; Rivolo, P. Mixed 1T-2H phase $\mathrm{MoS}_{2} /$ reduced graphene oxide as active electrode for enhanced supercapacitive performance. ACS Appl. Mater. Interfaces 2016, 8, 32842-32852. [CrossRef] [PubMed]

47. Ratha, S.; Rout, C.S. Supercapacitor electrodes based on layered tungsten disulfide-reduced graphene oxide hybrids synthesized by a facile hydrothermal method. ACS Appl. Mater. Interfaces 2013, 5, 11427-11433. [CrossRef] [PubMed]

48. Tu, C.-C.; Lin, L.-Y.; Xiao, B.-C.; Chen, Y.-S. Highly efficient supercapacitor electrode with two-dimensional tungsten disulfide and reduced graphene oxide hybrid nanosheets. J. Power Sources 2016, 320, 78-85. [CrossRef]

49. Chen, D.; Chen, W.; Ma, L.; Ji, G.; Chang, K.; Lee, J.Y. Graphene-like layered metal dichalcogenide/graphene composites: Synthesis and applications in energy storage and conversion. Mater. Today 2014, 17, 184-193. [CrossRef]

50. Zhang, C.; Yanagisawa, K.; Tao, H.; Onda, A.; Shou, T.; Kamiya, S. Solvothermal one-step synthesis and effect of carbon on properties of ruthenium sulfide catalysts. Catal. Lett. 2011, 141, 1311-1315. [CrossRef]

51. Zhang, C.; Yanagisawa, K.; Tao, H.; Onda, A.; Shou, T.; Kamiya, S. Oxygen reduction activity and methanol resistance of Ru-based catalysts prepared by solvothermal reaction. Catal. Lett. 2012, 142, 1128-1133. [CrossRef] 
52. Ziegelbauer, J.M.; Murthi, V.S.; O’Laoire, C.; Gullá, A.F.; Mukerjee, S.; O’Laoire, C.; Gullá, A.F.; Mukerjee, $\mathrm{S}$. Electrochemical kinetics and X-ray absorption spectroscopy investigations of select chalcogenide electrocatalysts for oxygen reduction reaction applications. Electrochim. Acta 2008, 53, 5587-5596. [CrossRef]

53. Li, Y.; Li, N.; Yanagisawa, K.; Li, X.; Yan, X. Hydrothermal synthesis of highly crystalline RuS 2 nanoparticles as cathodic catalysts in the methanol fuel cell and hydrochloric acid electrolysis. Mater. Res. Bull. 2015, 65, 110-115. [CrossRef]

54. Jeevanandam, P.; Koltypin, Y.; Gofer, Y.; Diamant, Y.; Gedanken, A. Sonochemical synthesis of nanocrystallites of ruthenium sulfide, RuS1.7. J. Mater. Chem. 2000, 10, 2769-2773. [CrossRef]

55. Chang, K.; Chen, W. L-Cysteine-Assisted Synthesis of Layered $\mathrm{MoS}_{2} /$ Graphene Composites with Excellent Electrochemical Performances for Lithium Ion Batteries. ACS Nano 2011, 5, 4720-4728. [CrossRef] [PubMed]

56. Xu, Y.; Sheng, K.; Li, C.; Shi, G. Self-Assembled Graphene Hydrogel via a One-Step Hydrothermal Process. ACS Nano 2010, 4, 4324-4330. [CrossRef] [PubMed]

57. Briggs, D. Surface Analysis by Auger and X-ray Photoelectron Spectroscopy; IM Publications: Charlton, UK, 2003.

58. Cai, T.; Song, Z.; Rodriguez, J.A.; Hrbek, J. Preparation and structural characterization of RuS 2 nanoislands on $\mathrm{Au}(111)$. J. Am. Chem. Soc. 2004, 126, 8886-8887. [CrossRef] [PubMed]

59. Jaegermann, W.; Kühne, H.-M. XPS analysis of the oxidation reaction of ruthenium-chalcogenide photoelectrodes. Appl. Surf. Sci. 1986, 26, 1-11. [CrossRef]

60. Smart, R.S.C.; Skinner, W.M.; Gerson, A.R. XPS of Sulphide Mineral Surfaces: Metal-deficient, Polysulphides, Defects and Elemental Sulphur. Surf. Interface Anal. 1999, 105, 101-105. [CrossRef]

61. Benoist, L.; Gonbeau, D.; Pfister-Guillouzo, G.; Schmidt, E.; Meunier, G.; Levasseur, A. X-ray photoelectron spectroscopy characterization of amorphous molybdenum oxysulfide thin films. Thin Solid Films 1995, 258, 110-114. [CrossRef]

62. Pollini, I. Photoemission study of the electronic structure of $\mathrm{CrCl}_{3}$ and $\mathrm{RuCl}_{3}$ compunds. Phys. Rev. B Condens. Matter Mater. Phys. 1994, 50, 2095-2103. [CrossRef]

63. Morgan, D.J. Resolving ruthenium: XPS studies of common ruthenium materials. Surf. Interface Anal. 2015, 1072-1079. [CrossRef]

64. Guo, Y.; Sun, X.; Liu, Y.; Wang, W.; Qiu, H.; Gao, J. One pot preparation of reduced graphene oxide (RGO) or $\mathrm{Au}(\mathrm{Ag})$ nanoparticle-RGO hybrids using chitosan as a reducing and stabilizing agent and their use in methanol electrooxidation. Carbon N. Y. 2012, 50, 2513-2523. [CrossRef]

65. Roppolo, I.; Chiappone, A.; Bejtka, K.; Celasco, E.; Chiodoni, A.; Giorgis, F.; Sangermano, M.; Porro, S. A powerful tool for graphene functionalization: Benzophenone mediated UV-grafting. Carbon N. Y. 2014, 77, 226-235. [CrossRef]

66. Lin, S.S.; Huang, Y.S.; Huang, C.R.; Lee, M.C. Raman investigation of RuS2. Solid State Commun. 1989, 69, 589-593. [CrossRef]

67. Kim, Y.L.; Choi, H.A.; Lee, N.S.; Son, B.; Kim, H.J.; Baik, J.M.; Lee, Y.; Lee, C.; Kim, M.H. RuO $\mathrm{R}_{2}-\mathrm{ReO}_{3}$ composite nanofibers for efficient electrocatalytic responses. Phys. Chem. Chem. Phys. 2015, 17, 7435-7442. [CrossRef] [PubMed]

68. Zequine, C.; Ranaweera, C.K.; Wang, Z.; Singh, S.; Tripathi, P.; Srivastava, O.N.; Gupta, B.K.; Ramasamy, K.; Kahol, P.K.; Dvornic, P.R.; et al. High per formance and flexible supercapacitors based on carbonized bamboo fibers for wide temperature applications. Sci. Rep. 2016, 6, 1-10. [CrossRef] [PubMed]

69. Zhou, J.; Lian, J.; Hou, L.; Zhang, J.; Gou, H.; Xia, M.; Zhao, Y.; Strobel, T.A.; Tao, L.; Gao, F. Ultrahigh volumetric capacitance and cyclic stability of fluorine and nitrogen co-doped carbon microspheres. Nat. Commun. 2015, 6, 8503. [CrossRef] [PubMed]

70. Shirley, D.A. High-Resolution X-ray Photoemission Spectrum of the Valence Bands of Gold. Phys. Rev. B 1972, 5, 4709-4714. [CrossRef]

71. Stoller, M.D.; Ruoff, R.S. Best practice methods for determining an electrode material's performance for ultracapacitors. Energy Environ. Sci. 2010, 3, 1294-1301. [CrossRef]

(C) 2017 by the authors. Licensee MDPI, Basel, Switzerland. This article is an open access article distributed under the terms and conditions of the Creative Commons Attribution (CC BY) license (http:// creativecommons.org/licenses/by/4.0/). 